\title{
HIGH-FREQUENCY OSCILLATIONS IN PLASMA OF LOWER HYBRID CAVITIES
}

\author{
N.A. Azarenkov, D.V. Chibisov \\ V.N. Karazin Kharkiv National University, Kharkiv, Ukraine \\ E-mail: dmitriychibisov@karazin.ua
}

The problem of the presence of high-frequency oscillations in lower hybrid cavities in the plasma of the earth's ionosphere is considered. It is assumed that the oscillations in the cavity are excited due to the ring ion current across the magnetic field, in addition to the mechanism of the Hall current arising from the radial inhomogeneity of the plasma density. The radial dependence of the density of the ring ion beam is also taken into account.

PACS: 52.35.Qz, 52.35.Ra, 94.20.wf

\section{INTRODUCTION}

The lower hybrid cavities (LHC) are axisymmetric spatially localized solitary structures in the ionosphere, elongated along the geomagnetic field. They are characterized by localized oscillations of the electric field at frequencies near the lower hybrid resonance as well as a decrease in density to several tens of percent [1]. Currently, there are two class of theories applied to LHC. The first class [2 - 4] includes the theory of strong turbulence of the lower hybrid collapse, which suggests that the depletion of density and oscillations of the electric field are directly related to the ponderomotive force. However, it was stated in [5] that the theoretical conclusions of the theory of strong turbulence do not correspond to the statistical properties of most of the observed cavities. Second class [6, 7] includes linear theories which suggest that density depletions already exist, and use the spatial properties of density depletions to determine the characteristics of low-hybrid waves. It is assumed that the excitation mechanism of the lower hybrid waves is the Hall current created by electron drift across the gradient of a density profile. This current is not canceled by ions, which, for these oscillation frequencies, can be considered unmagnetized in the cavity. As for the mechanism of wave excitation due to the current across the density gradient, this assumption of linear theories is generally true, but there is every reason to believe that ions moving in the cavity also participate in the initiation of lower-hybrid waves. Observations by spacecraft showed that ions in a cavity have an increased energy across the magnetic field compared to ions of the surrounding plasma. Thus, a group of ions may appear in the cavity, which encircles the axis of depletion. These ions produce an azimuth current, which will be another factor besides the Hall current to amplify the lower hybrid waves.

In [8] the excitation of electrostatic lower hybrid waves in a cylindrically symmetric magnetized plasma by ions encircles the plasma axis was investigated. The Gaussian plasma density distribution over the radius was considered. It was shown that the instability is excited as a result of the Cherenkov interaction of resonant ionsrotating around the plasma axis with lower hybrid waves. In [9] the excitation of lower hybrid waves in a plasma with an ion-ring distribution with a radially inhomogeneous density in a homogeneous plasma was studied. The effect of inhomogeneity of the ring ion beam on the conditions for the excitation of waves was established. In the present paper the excitation of lower hybrid waves by ion beam encircling of axis of symmetry, taking into account its in homogeneity, is considered as applied to the plasma conditions of lower hybrid cavities.

\section{INSTABILITY OF LOWER HYBRID WAVES IN PLASMA OF LHC}

The radial density profile in plasma of LHC has the form of an inverted Gaussian distribution [1]

$$
n(r)=n_{0}\left(1-a \exp \left(-\frac{r^{2}}{2 r_{0}^{2}}\right)\right),
$$

where $r_{0}$ is the length of the inhomogeneity of plasma density, $a$ is the positive constant, equal to the depth of the cavity. Suppose that a part of plasma ions in the cavity encircle the axis of depletion and thereby form an ion ring beam. The presence of such ions in the cavity can be explained by their energization, which is confirmed by observations. Assume, that density profile of ion ring beam in the cavity is

$$
n_{b}(r)=n_{0 b}\left(1-a \exp \left(-\frac{r^{2}}{2 r_{0}^{2}}\right)\right)\left(-\frac{r^{2}}{2 r_{b}^{2}}\right),
$$

which takes into account the distribution of plasma density in the cavity, as well as the inhomogeneity of the profile of the beam itself, whose density outside the cavity tends to zero. The characteristic length of the inhomogeneity of the ion beam $r_{b}$ actually characterizes the level of its heating and is equal to the thermal gyro radius of heated ions in the cavity. It is assumed that $r_{b}<r_{0}$. The part of ions encircling the cavity axis are considered small in comparison with the bulk of plasma ionsso it is assumed that $n_{0 b}<<n_{0}$. Distribution (2) has a minimum at $r=0$, and a maximum at

$$
r_{m}=\sqrt{2} r_{0} \ln ^{1 / 2}\left(a\left(1+\frac{r_{b}^{2}}{r_{0}^{2}}\right)\right)
$$

when the condition

$$
a\left(1+\frac{r_{b}^{2}}{r_{0}^{2}}\right)>1
$$

is satisfied. Otherwise, the distribution has only a maximum at $r=0$. In other words, the ion flux, encircling the axis of depletion has a density maximum at a radius (3) different from zero if the depth of the cavity is sufficiently large so that the condition (4) is true. Otherwise, when the depth of the cavity is small and the condition (4) is not fulfilled, the density of ions encircling the axis 
of depletion is decreasing for all radius values. Figure shows examples of two cases of density distribution of ion beam, where curve 1 corresponds to the case when condition (4) is satisfied, and curve 2, when (4) is not satisfied

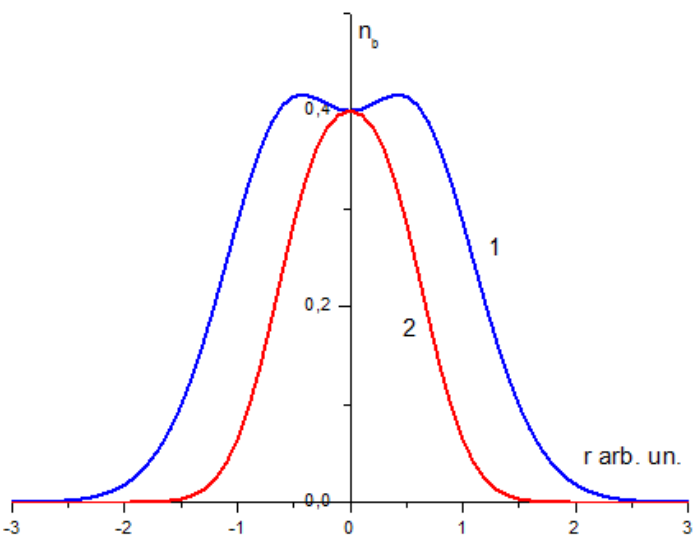

Dependence of the ion beam density in the cavity on the radiuswhen condition (4) is satisfied, 1, and not satisfied, 2

Let us now consider the conditions for the excitation of lower hybrid waves in the plasma of the cavity by a ring ion beam having a radial density profile as (2). Dispersion equation for lower hybrid waves in a cylindrically symmetric plasma has the form [9]

$$
\begin{gathered}
\varepsilon(K, m, \omega)=1+\frac{\omega_{p e}^{2}}{\omega_{c e}^{2}} \sin ^{2} \theta-\frac{\omega_{p e}^{2}}{\omega^{2}} \cos ^{2} \theta+ \\
+\sum_{i, b} \frac{1}{k^{2} \lambda_{D i, b}^{2}}\left(1+i \sqrt{\pi} z_{i, b} W\left(z_{i, b}\right)\right)=0,
\end{gathered}
$$

where $m$ and $K\left(k_{\perp}, k_{z}\right)$ are azimuthal, transverse and longitudinal wavenumbers, $\lambda_{D \alpha}$ is the Debye length, $\theta=\arctan \left(k_{\perp} / k_{z}\right)$ is the angle of wave propagation relative to the magnetic field, $\omega_{p e}$ is the plasma frequency

$$
\begin{gathered}
z_{i}=\omega / \sqrt{2} k_{\perp} v_{T i}, z_{b}=\left(\omega+m \omega_{c b}-m \omega_{b^{*}}\right) / \sqrt{2} k_{\perp} v_{T b}, \\
\omega_{b^{*}}=-\omega_{c b} \rho_{T b}^{2}\left(d \ln n_{b}\left(r_{s}\right) / r_{s} d r_{s}\right)
\end{gathered}
$$

is the drift frequency of beam ions and $n_{b}\left(r_{s}\right)$ is the density of beam ions (2), where radial coordinate $r$ is replaced by variable $r_{s}=|m| / k_{\perp}$. Equation (5) in the short wavelength limit $|m|>>1$ determines the dispersion properties of cylindrical waves $J_{m}\left(k_{\perp} r\right)$ which are Bessel functions. The value of radius $r_{s}=|m| / k_{\perp}$ separates the aperiodic and oscillatory parts of Bessel function, which approximately is equal the radial coordinate of its first maximum.

The dielectric permittivities for beam and plasma ions in (5) correspond to the approximation of null magnetic field, assuming that the ions move in straight orbits. However, the cyclotron motion of beam ions in expressions for $z_{b}$ is taken into account by the term $m \omega_{c b}$ which is the Doppler shift causedby theirrotation around the axis of depletion. We now suppose that inequality $\left|z_{i}\right| \gg>1$ is met. However we assume that Che- renkov interaction of resonant ions rotating around axis for the beam ions is significant, i.e. equality $\left|z_{b}\right| \simeq 1$ hold. This equality is possible when the resonant condition $\left|\omega+m \omega_{c b}-m \omega_{b^{*}}\right| \approx \sqrt{2} k_{\perp} v_{T b}$ is satisfied. In this case the dispersion relation takes the form [9]

$$
\begin{gathered}
\varepsilon(K, m, \omega)=1+\frac{\omega_{p e}^{2}}{\omega_{c e}^{2}} \sin ^{2} \theta-\frac{\omega_{p e}^{2}}{\omega^{2}} \cos ^{2} \theta-\frac{\omega_{p i}^{2}}{\omega^{2}} \sin ^{2} \theta \\
+\frac{1}{k^{2} \lambda_{D b}^{2}}+i \frac{1}{k^{2} \lambda_{D b}^{2}} \sqrt{\pi} z_{b} \exp \left(-z_{b}^{2}\right)=0
\end{gathered}
$$

Suggesting that $k_{z} / k<m_{e} / m_{i}$, as well as $k^{2} \lambda_{D b}^{2}>1$ we get the real frequency $\operatorname{Re} \omega_{m}(K)$ and growth rate $\gamma_{m}(K)$ for lower hybrid waves

$$
\begin{gathered}
\operatorname{Re} \omega_{m}\left(k_{\perp}\right)=\omega_{L H}=\frac{\omega_{p i}}{\sqrt{1+\omega_{p e}^{2} / \omega_{c e}^{2}}}, \\
\gamma_{m}\left(k_{\perp}\right) \approx-\sqrt{\pi} \omega_{L H} \frac{\omega_{p b}^{2}\left(r_{0}\right)}{\omega_{p i}^{2}} \frac{\omega_{L H}^{2}}{2 k_{\perp}^{2} v_{T b}^{2}} \\
\times \frac{\left(\omega_{L H}+m \omega_{c b}-m \omega_{b^{*}}\right)}{\sqrt{2} k_{\perp} v_{T b}} \exp \left(-z_{b}^{2}\right) .
\end{gathered}
$$

From eq. (8) it follows that the growth rate is positive, and therefore the lower hybrid waves are unstable when the azimuthal wave number satisfies the conditions $m<0$ and

$$
|m|>\frac{\omega_{L H}}{\left(\omega_{c b}-\omega_{b^{*}}\right)}>1 .
$$

Condition (9) indicates that for the radial coordinates of ion ring beam where $\nabla n_{b}(r)>0$ unstable waves have a greater absolute value of azimuthal wave numbers, than where $\nabla n_{b}(r)<0$. However, Figure shows that the region along radius with a negative density gradient of the ion beam prevails; therefore, lower hybrid waves with lower azimuthal wave numbers occupy a larger region. In addition, if the depth of the cavity is insignificant, so that condition (4) is not fulfilled, a part of radius with a positive density gradient of the ion beam is completely absent. Thus, taking into account the inhomogeneity of the ion beam along the radius corrects the azimuthal wave numbers down.

Now we estimate the electric field strength in the lower hybrid wave in the cavity and for this we use the saturation level of lower hybrid instability due to a ringion beam in a cylindrically symmetric plasma which was obtained in [9]. It was assumed that the instability is saturated due to effect of scattering of beam ions by the random fluctuations of the electrostatic turbulence [10]. It is established, that the level of saturation of instability is

$$
\frac{e_{b}\langle\Phi(r)\rangle}{T_{b}} \sim \frac{\gamma_{m}\left(k_{\perp}\right)}{\omega_{L H}} \frac{\omega_{c b}}{\omega_{L H}},
$$

where $\langle\Phi(r)\rangle$ is a root-mean-square amplitude of the perturbed electrostatic potential, $T_{b}$ is the temperature of ion beam, $\omega_{c b}$ is the ion cyclotron frequency. Since for the ionosphere the condition $\omega_{c b}<<\omega_{L H}$, is satisfied, then the oscillation energy is much lower than ion 
temperature. To estimate the strength of the electric field created by lower-hybrid oscillations we assume that the temperature of ions is about $0.5 \mathrm{eV}$, wavelength is $\lambda=2 \pi r / m$, where $r$ is the oscillation localization radius, which in order of magnitude is equal to the thermal Larmor radius of the ions of the ring beam, $r=\rho_{T b}$, and $m$ is the azimuthal wavenumber, which determined by (9). Electric field strength in density depletion we estimate as

$$
\langle E\rangle \sim \frac{\langle\Phi(r)\rangle}{\lambda / 2}=\frac{m\langle\Phi(r)\rangle}{\pi \rho_{T b}} .
$$

Considering (9) and (10), we get

$$
\langle E\rangle \sim \frac{T_{b}}{\pi \rho_{T b} e} .
$$

Assuming $\rho_{T b}=5 \mathrm{~m}$ for cavity conditions, we obtain $\langle E\rangle \sim 0.03 \mathrm{~V} / \mathrm{m}$, which is generally consistent with the measurement data.

\section{CONCLUSIONS}

Energization of ions in the cavity leads to the appearance of a group of ions that encircle the axis of density depletion and thereby create an azimuth current. The radial density profile of a ring ion beam is determined by the relation (2). This density profile can have a local maximum or on the axis of the cavity or on a radius not equal to zero (3), depending on the depth of the cavity, which is determined by the condition (4).

Ions encircling the cavity axis lead to the growth of lower hybrid waves, due to the Cherenkov interaction of resonant ions with waves. These waves are unstable when the azimuthal wave number satisfies the condition (7). Taking into account the radial inhomogeneity of the density distribution of the ring ion beam decrease the values of azimuthal wave numbers. The presented instability mechanism is an addition to the mechanism of the Hall current, created by electron drift due to the density profile gradient [1].

The saturation of the lower hybrid instability in the cavity occurs due to the effect of beam ion scattering by random fluctuations of electrostatic turbulence. An es- timate of the electric field strength in the lower hybrid wave is $\langle E\rangle \sim 0.03 \mathrm{~V} / \mathrm{m}$, which is generally consistent with the measurement data.

\section{REFERENCES}

1. P.W. Schuck, J.W. Bonnell, P.M. Kintner. A review of lower hybrid solitary structures // IEEE Trans. Plasma Sci. 2003, v. 31, № 6, p. 1125-1177.

2. V.D. Shapiro, V.I. Shevchenko, G.I. Solov'ev, et al. Wave collapse at the lower-hybrid resonance // Phys. Fluids B. 1993, v. 5, № 9, p. 3148-3162.

3. P.A. Robinson. Scalings, spectra, and statistics of strong wave turbulence // Phys. Plasmas. 1996, v. 3, № 1, p. 192-201.

4. V.D. Shapiro. Modulational interaction of the lowerhybrid waves with a kinetic-Alfven mode // Phys. Rev. Lett. 1998, v. 81, № 6, p. 3415-3418.

5. P.W. Schuck and G.I. Ganguli. The role of lowerhybrid-wave collapse in the auroral ionosphere // Phys. Rev. Lett. 2002, v. 89, № 6, p. 065002-1065002-4.

6. C.E. Seyler. Lower hybrid wave phenomena associated with densitydepletions // J. Geophys. Res. 1994, v. 99, № A10, p. 19 513-19 525.

7. P.W. Schuck, C.E. Seyler, et al. Theory simulation and observation of bound states associated with lower hybrid solitary structures // J. Geophys. Res. 1998, v. 103, № A4, p. 6935-6953.

8. V.S. Mikhailenko, D.V. Chibisov, et al. Electrostatic instabilities of a multicomponent plasma with ions gyrating around the axis of the plasma column // Plasma Phys. Reps. 1997, v. 23, № 1, p. 44-52.

9. D.V. Chibisov, V.S. Mikhailenko. The lower hybrid waves driven by inhomogeneousion-ring distribution // Problems of Atomic Science and Technology. Series “Plasma Physics”. 2012, № 6, p. 99-101.

10. C.T. Dum, T.H. Dupree. Nonlinear stabilization of high-frequency instabilities in a magnetic field // Phys. Fluids. 1971, v. 13, № 8, p. 2064-2081.

Article received 31.05.2019

\section{ВЫСОКОЧАСТОТНЫЕ КОЛЕБАНИЯ ПЛАЗМЫ НИЖНЕГИБРИДНЫХ ПОЛОСТЕЙ}

\section{Н.А. Азаренков, Д.В.Чибисов}

Рассматривается проблема присутствия высокочастотных колебаний в нижнегибридных полостях в плазме ионосферы Земли. Предполагается, что колебания в полости возбуждаются за счет тока кольцевого ионного пучка поперек магнитного поля в дополнение к механизму тока Холла, возникающего из-за радиальной неоднородности плотности плазмы. Учитывается также радиальная зависимость плотности кольцевого ионного пучка.

\section{ВИСОКОЧАСТОТНІ КОЛИВАННЯ ПЛАЗМИ НИЖНЬОГІБРИДНИХ ПОРОЖНИН}

\section{М.О. Азарснков, Д.В.Чібісов}

Розглядається проблема присутності високочастотних коливань у нижньогібридних порожнинах у плазмі іоносфери Землі. Передбачається, що коливання в порожнині збуджуються за рахунок струму кільцевого іонного пучка поперек магнітного поля на додаток до механізму струму Холла, що виникає через радіальну неоднорідність щільності плазми. Враховується також радіальна залежність щільності кільцевого іонного пучка. 